\title{
Thickness and structure of the Martian crust from InSight seismic data
}

Brigitte Knapmeyer-Endrun ${ }^{1 *}$, Mark P. Panning ${ }^{2}$, Felix Bissig ${ }^{3}$, Rakshit Joshi ${ }^{4}$, Amir Khan $^{3,5}$, Doyeon Kim ${ }^{6}$, Vedran Lekić ${ }^{6}$, Benoit Tauzin ${ }^{7,8}$, Saikiran Tharimena ${ }^{2,9}$, Matthieu Plasman ${ }^{10}$, Nicolas Compaire ${ }^{11}$, Raphael F. Garcia ${ }^{11}$, Ludovic Margerin ${ }^{12}$, Martin Schimmel ${ }^{13}$, Éléonore Stutzmann ${ }^{10}$, Nicholas Schmerr ${ }^{6}$, E. Bozdağ ${ }^{14}$, Ana-Catalina Plesa ${ }^{15}$, Mark A. Wieczorek ${ }^{16}$, Adrien Broquet ${ }^{17,16}$, Daniele Antonangeli ${ }^{18}$, Scott M. McLennan ${ }^{19}$, Henri Samuel ${ }^{10}$, Chloé Michaut $^{7,20}$, Lu Pan ${ }^{21}$,Suzanne E. Smrekar ${ }^{2}$, Catherine L. Johnson ${ }^{22,23}$, Nienke Brinkman ${ }^{3}$, Anna Mittelholz $^{3}$, Attilio Rivoldini ${ }^{24}$, Paul M. Davis ${ }^{25}$, Philippe Lognonné ${ }^{10,20}$, Baptiste Pinot ${ }^{11}$, JohnRobert Scholz ${ }^{4}$, Simon Stähler ${ }^{3}$, Martin Knapmeyer ${ }^{15}$, Martin van Driel ${ }^{3}$, Domenico Giardini ${ }^{3}$, W. Bruce Banerdt ${ }^{2}$

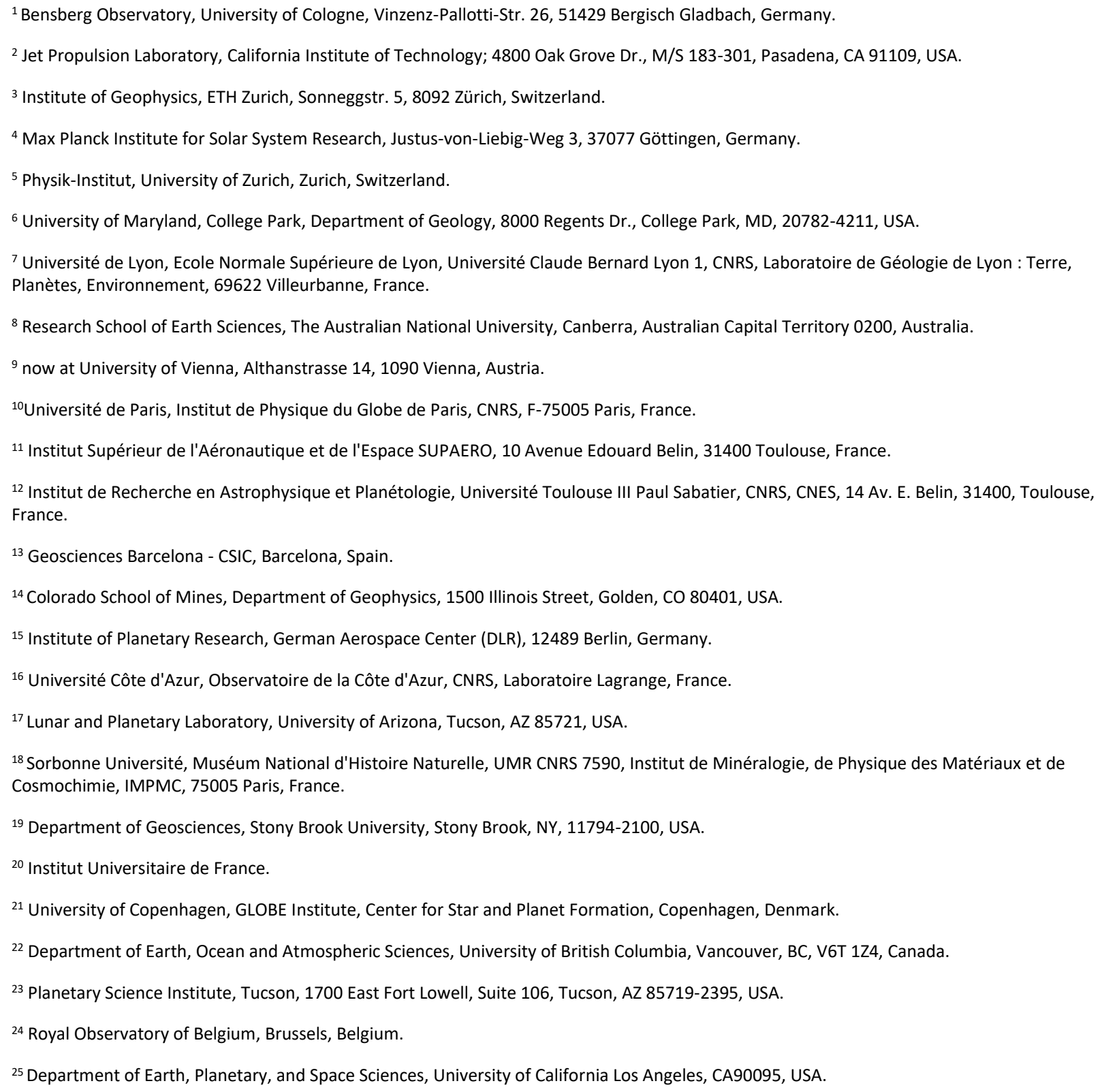


*Correspondence to: bknapmey@uni-koeln.de.

\begin{abstract}
A planet's crust bears witness to the history of planetary formation and evolution, but for Mars, no absolute measurement of crustal thickness was available. Here, we determine the structure of the crust beneath the InSight landing site on Mars using both marsquake recordings and the ambient wavefield. Analyzing seismic phases that are reflected and converted at subsurface interfaces, we find that the observations are consistent with models with at least two, and possibly three interfaces. If the second interface is the boundary of the crust, the thickness is $20 \pm 5 \mathrm{~km}$, while if the third interface is the boundary, the thickness is $39 \pm 8 \mathrm{~km}$. Global maps of gravity and topography allow extrapolation of this point measurement to the whole planet, showing that the average thickness of the Martian crust lies between 24 and $72 \mathrm{~km}$. Independent bulk composition and geodynamic constraints show that the thicker model is consistent with the abundances of crustal heat-producing elements observed for the shallow surface, whereas the thinner model requires greater concentration at depth.
\end{abstract}

\title{
One Sentence Summary:
}

Based on multiple approaches, direct seismic measurements constrain global crustal thickness, geochemistry and geodynamic processes.

Planetary crusts form as a result of mantle differentiation and subsequent magmatic processes, including partial melting of mantle reservoirs that may continue to the present day (1). For Mars, the cratering record shows that much of its crust formed early in the planet's history and was accompanied by substantial volcanism (2,3). During both the initial crystallization of a putative magma ocean as well as later-stage partial melting, incompatible components, including heat-producing elements (HPE) and volatiles, concentrated in the melt and were largely sequestered into the crust. The thickness of the crust of Mars thus provides fundamental constraints on how the planet differentiated, how incompatible elements were partitioned among the major silicate reservoirs, and how the planet evolved thermally and magmatically over geologic time (4-6).

Previous estimates of the crustal thickness of Mars and its spatial variations were made by modeling the relationship between gravity and topography. By assuming Airy isostasy and using a restrictive range of crustal densities of $2700-3100 \mathrm{~kg} \mathrm{~m}^{-3}$, the average crustal thickness of the planet was reported to be $57 \pm 24$ $\mathrm{km}$ (7). More recent analyses, however, have used elemental abundances of the surface (8) along with major element chemistry of Martian meteorites to argue that the crust could be considerably denser, with values close to $\sim 3300 \mathrm{~kg} \mathrm{~m}^{-3}$. If these higher densities were representative of the underlying crust, the gravity data would allow average crustal thicknesses up to $110 \mathrm{~km}(9)$. In contrast, bulk crustal densities lower than previously assumed $\left(\sim 2600 \mathrm{~kg} \mathrm{~m}^{-3}\right)$ have been inferred from gravity analyses and would allow a thinner average crustal thickness (10). Low densities were confirmed locally for the near-surface sediments in Gale crater (11) as well as the pyroclastic deposit of the Medusa Fossae Formation (12). Low bulk crustal densities could result from either substantial porosity or the presence of buried silica- and feldspar-rich rocks (13). Silica-rich magmatic rocks are potentially consistent with ancient evolved lithologies identified in Martian meteorite breccias (14).

We used data from the Seismic Experiment for Interior Structure (SEIS) on NASA's InSight mission (15) to provide an absolute measurement of Mars' crustal thickness and layering. Our assessment of the crustal structure at the landing site is based on a combination of methods using both converted and reflected seismic phases, in order to resolve trade-offs between the depth of a layer and its seismic velocity (16). By calculating receiver functions $(17,18)$, we extracted P-to-S conversions from the P-wave coda of three seismic events with the clearest P-wave onsets and polarizations. In addition, we applied seismic interferometric techniques by calculating autocorrelations of both ambient noise and event coda using the 
vertical component. Under the assumption of a diffuse wavefield, as expected in the case of noise from homogeneously distributed, uncorrelated sources as well as in the coda of high-frequency events, the correlations can be interpreted as zero-offset vertical reflection responses (19). By focusing on the reflected wavefield, the autocorrelations provide independent and complementary information to the receiver function conversion-based methods that make use of the transmitted wavefield (20).

In a previous study (18), we already considered P-to-S receiver functions for two of the same events, but only inverted for the properties of the interface at the base of the shallowest layer (interpreted there as a transition from fractured to unfractured basalt within the crust), causing the first converted arrival at $2.4 \mathrm{~s}$. Including an additional event and applying extensive re-analysis to the data (16), the P-to-S receiver functions for 9 different processing methods (16) show three consistent positive arrivals within the first 8 $\mathrm{s}$, but no clear and consistent negative arrivals or later phases (Fig. 1A). As all three events are located at epicentral distances between $25^{\circ}$ and $59^{\circ}(21,22)$, no strong move-out of either direct arrivals or multiple reflections is expected, which impedes the unambiguous identification of multiples. The third positive arrival at 7.2-7.5 s could be either simply a PpPs multiple of the first arrival at $2.4 \mathrm{~s}$ (ray path 3 in Fig. 2B), or contain additional energy from a direct conversion from a third, deeper discontinuity (ray path 3 in Fig. 2D). We applied two inversion approaches to the P-to-S receiver functions (16), and both can match the three clear peaks with either two (Fig. 2A-B) or three interfaces (Fig. 2C-D). In both inversion approaches, our models showed robust and consistent depths of the two shallowest interfaces. The first layer with a thickness of 6-11 km and an S-wave velocity between 1.2 and $2.1 \mathrm{~km} / \mathrm{s}$ is consistent with the previous results for the shallow crust (18), whereas a second interface is found at $15-25 \mathrm{~km}$ depth independent of the model parameterization. The third interface, the existence of which is supported but not absolutely required by the data, showed greater variability in depth between different inversion choices and generally required a smaller velocity contrast at the base of this layer than for the shallower second interface (Figs. S18, S19). Based on the ensemble of models from the two inversion approaches, our results are consistent with either a local crustal thickness at the InSight landing site of $15-25 \mathrm{~km}$, when the base of layer 2 is the Moho (thin crust models), or 27-47 km, when the base of layer 3 is the Moho (thick crust models; Figs. 2, S18, S19). S-to-P receiver functions can also be calculated for 2 events (S0173a and S0235b; Figs. S4, S6, S7) and both show a signal consistent with conversion at the first interface, while S0235b also shows possible arrivals consistent with deeper conversions (16). Further support for the P-to-S receiver function-derived models is provided by waveform fits in inversions for source mechanisms (16), where a strong interface around $24 \mathrm{~km}$ depth is required to match S-precursors.

Vertical component autocorrelations based on different data sets and processing algorithms $(16,23)$ show consistent energy maxima in the 5 to $6 \mathrm{~s}, 10$ to $11 \mathrm{~s}$, and 20 to $21.5 \mathrm{~s}$ time ranges (Fig. 3). Comparison with predicted arrival times from representative models produced by the receiver function inversion shows that these energy maxima can be explained by P-wave reflections in those models interacting with the first two interfaces, without any clear observations requiring the third interface. Previously published autocorrelations (24) contain an arrival near $10 \mathrm{~s}$ that is consistent with our results, and which can be explained as a P-wave reflection from the bottom of the second layer at around $22 \mathrm{~km} \mathrm{depth}$. A second arrival reported by (24) near $20 \mathrm{~s}$, that is also present in many of the autocorrelation functions calculated here, is consistent with a multiple reflection from that layer (Fig. 3). These arrivals were interpreted by Deng and Levander (24) as P and S reflections, respectively, from a crust-mantle discontinuity at a depth of $35 \mathrm{~km}$. However, we do not expect a strong $S$ reflection in a vertical autocorrelation as vertically propagating $\mathrm{S}$ waves are horizontally polarized. Interpreting the second arrival as a multiple $\mathrm{P}$ reflection instead is consistent with our receiver function-derived results and more likely to be observed in a vertical component autocorrelation. The previously published crustal thickness estimate of $35 \mathrm{~km}$ based on autocorrelations (24) is consistent with the possible range of the thick crust models, but the specific arrivals identified in that study are more consistent with a reflection and multiple from the shallower second interface around $20 \mathrm{~km}$ depth. 
We inverted for the thickness of the crust at global scale using the seismically-estimated thickness at the InSight landing site and observed gravity field as constraints (16). Our models consider the gravity of hydrostatic relief along density interfaces beneath the lithosphere, surface relief, variations in thickness of a constant density crust, and the low-density polar cap deposits (25). We employed several different interior pre-landing models (26) that specify the density profile of the mantle and core, and for each, we constructed crustal thickness models for all permissible crustal densities. For a given seismic thickness, the mean thickness of the crust depends almost exclusively on the density contrast across the crust-mantle interface (Fig. S22). To ensure that the thickness of the crust is positive within the major impact basins, each reference model has a maximum permissible crustal density. If the thin crust seismic model is used as a constraint, the global mean crustal thickness is predicted to lie between 24 and $38 \mathrm{~km}$ and the maximum permissible density of the crust is $2850 \mathrm{~kg} \mathrm{~m}^{-3}$ (Figs. 4, S22, S23). For the thick crust seismic model, the average crustal thickness lies between 39 and $72 \mathrm{~km}$ and the maximum permissible crustal density is 3100 $\mathrm{kg} \mathrm{m}^{-3}$ (Figs. 4, S22, S23). For both seismic constraints, the crustal density is substantially less than would be expected based on the composition of surface materials (9), which is close to $3300 \mathrm{~kg} \mathrm{~m}^{-3}$. The lower bulk densities are signatures of highly altered layers and can be accounted for by the presence of more than $5 \%$ porosity in the crust on average, the presence of fluids or low-density cements filling fractures and pore space, the existence of abundant petrologically evolved felsic rocks beneath the surface layer, or a combination thereof.

The seismic observations argue for a relatively thin crust, or at least thinner than some earlier predictions (9), providing constraints on crustal heat production and the degree of planetary silicate differentiation (Fig. 4). As the present-day crustal thickness is the outcome of the planet's differentiation history $(27,28)$, geodynamic and geologic modeling can place constraints on the composition of the crust and of the mantle, and on the cooling rate of the planet (16). Our results indicate that average crustal thickness models that are consistent with the thick crust seismic model are compatible with currently accepted bulk $(29,30)$ and crustal $(8,31)$ heat producing element contents, and the occurrence of present-day melting only in an ascending plume below the thickened crust of the Tharsis province (Fig. S27). Such a scenario implies a crust that is about 13 times more enriched in heat producing elements than the primitive mantle (Fig. S24), consistent with 55-70\% of the Martian heat producing elements being sequestered into the crust. In contrast, the thin crust seismic model requires a crust that is about 21 times more enriched than a relatively cold primitive mantle (Fig. S25). This is more than two times larger than estimates from gamma-ray spectroscopy data which constrains the surface layer of the crust (Table S6) and would point towards an enrichment in heat-producing elements beneath the surface layer (16). Furthermore, this would call for an efficient process of incompatible element extraction from the mantle, possibly by upward segregation during the solidification of a magma ocean, or by a secondary differentiation mechanism, as for the continental crust of Earth. In both crustal models, assuming a Wänke and Dreibus (29) bulk composition, the present-day heat flux is predicted to lie between 20 and $25 \mathrm{~mW} \mathrm{~m}^{-2}$ (Fig. 4). The depth to the crustmantle boundary, as well as layering in the crust can further constrain crustal magnetization amplitudes, depending on whether the magnetization is carried in upper or lower crustal layers, or both (16). We can also investigate whether crustal thickness and density models are consistent with moment-of-inertia measurements and constraints on the properties of Mars core from the $\mathrm{k}_{2}$ tidal Love number (16). Generally, these constraints are easier to match for most mantle composition models with the thick crust seismic models, although some models also allow for the thin crust model. Overall, when considering geodynamic, geochemical, and geodetic constraints, the thin crust models place tighter constraints on the density and enrichment of heat producing elements within the crust, as well as on the mantle composition, than the thick crust models, but neither of the two can be excluded.

\section{References and Notes:}

1. L. T. Elkins-Tanton, Magma oceans in the inner solar system. Annu. Rev. Earth. Planet. Sci. 40, 113-139 (2012). 
2. M. Grott et al., Long-term evolution of the Martian crust-mantle system. Space Sci. Rev. 174, 49-111 (2013).

3. F. Nimmo, K. Tanaka, Early crustal evolution of Mars. Annu. Rev. Earth Planet. Sci. 33, 133161 (2005).

4. D. Breuer, W.B. Moore, "10.08-Dynamics and thermal history of the terrestrial planets, the Moon, and Io", in Treatise on Geophysics, G. Schubert Ed. (Elsevier, Oxford, ed. 2, 2015), pp. 255-305.

5. S. A. Hauck II, R. J. Philips, Thermal and crustal evolution of Mars. J. Geophys. Res. 107, 5052 (2002).

6. A.-C. Plesa et al., The thermal state and interior structure of Mars. Geophys. Res. Lett. 45, 12198-12209 (2018).

7. M. A. Wieczorek, M. T. Zuber, Thickness of the Martian crust: Improved constraints from geoid-to-topography ratios. J. Geophys. Res. 109, E01009 (2004).

8. B. C. Hahn, S. M. McLennan, E. C. Klein, Martian surface heat production and crustal heat flow from Mars Odyssey Gamma-Ray spectrometry. Geophys. Res. Lett. 38, L14203 (2011).

9. D. Baratoux et al., Petrological constraints on the density of the Martian crust. J. Geophys. Res. 119, 1707- 1727 (2014).

10. S. Goossens et al., Evidence for a low bulk crustal density for Mars from gravity and topography. Geophys. Res. Lett. 44, 7686- 7694 (2017).

11. K. W. Lewis et al., A surface gravity traverse on Mars indicates low bedrock density at Gale crater. Science 363, 535-537 (2019).

12. L. Ojha, K. Lewis, The density of the Medusae Fossae Formation: Implications for its composition, origin, and importance in Martian history. J. Geophys. Res. 123, 1368-1379 (2018).

13. V. Sautter et al., In situ evidence for continental crust on early Mars. Nature Geoscience 8, 605609 (2015).

14. M. Humayun et al., Origin and age of the earliest Martian crust from meteorite NWA7533. Nature 503, 513-516 (2013).

15. P. Lognonné et al., SEIS: Insight's Seismic Experiment for Internal Structure of Mars. Space. Sci. Rev. 215, 12 (2019).

16. Methods and additional materials are available as supplementary materials on Science Online.

17. C. A. Langston, Structure under Mount Rainier, Washington, inferred from teleseismic body waves. J. Geophys. Res. 84, 4749-4762 (1979).

18. P. Lognonné et al., Constraints on the shallow elastic and anelastic structure of Mars from InSight seismic data. Nature Geoscience 13, 213-220 (2020).

19. K. Wapenaar, D. Draganov, R. Snieder, X. Campman, A. Verdel, Tutorial on seismic interferometry: Part 1-Basic principles and applications. Geophysics 75, 75A195-75A209 (2010).

20. D. Kim, V. Lekić, Groundwater variations from autocorrelations and receiver functions. Geophys. Res. Lett. 46, 13722-13729 (2019).

21. D. Giardini et al., The seismicity of Mars. Nature Geoscience 13, 205- 212 (2020).

22. A. Khan et al., Imaging the upper mantle structure of Mars with InSight seismic data. Science, submitted (2021).

23. N. Compaire et al., Autocorrelation of the ground vibrations recorded by the SEIS-InSight seismometer on Mars. J. Geophys. Res. 126, e2020JE006498, doi:10.1029/2020JE006498 (2021).

24. S. Deng, A. Levander, Autocorrelation Reflectivity of Mars, Geophys. Res. Lett. 47, e2020GL089630 (2020).

25. M. A. Wieczorek, M. Beuthe, A. Rivoldini, T. Van Hoolst. Hydrostatic interfaces in bodies with nonhydrostatic lithospheres, J. Geophys. Res. Planets 124, doi:10.1029/2018JE005909 (2019). 
26. S. E. Smrekar et al., Pre-mission InSights on the Interior of Mars. Space Sci Rev 215, 3, doi:10.1007/s11214-018-0563-9 (2019).

27. H. Samuel, P. Lognonné, M. Panning, V. Lainey, The rheology and thermal history of Mars revealed by the orbital evolution of Phobos, Nature 569, 523-527 (2019).

28. M. Thiriet, C. Michaut, D. Breuer, A. C. Plesa, Hemispheric dichotomy in lithosphere thickness on Mars caused by differences in crustal structure and composition, J. Geophys. Res.

Planets 123, 823-848 (2018).

29. H. Wänke, G. Dreibus, Chemistry and accretion history of Mars, Philos. Trans. R. Soc. London. Ser. A Phys. Eng. Sci. 349, 285-293 (1994).

30. G. J. Taylor, The bulk composition of Mars, Geochemistry 73, 401-420 (2013).

31. S. R Taylor, S. M McLennan, Planetary Crusts: Their composition, origin and evolution (Cambridge Univ. Press, Cambridge, 2009).

32. InSight Mars SEIS Data Service, SEIS raw data, InSight Mission, IPGP, JPL, CNES, ETHZ, ICL, MPS, ISAE-Supaero, LPG, MFSC, https://doi.org/10.18715/SEIS.INSIGHT.XB_2016 (2019).

33. D. L. Abt, K. M. Fischer, S. W. French, H. A. Ford, H. Yuan, B. Romanowicz, North American lithospheric discontinuity structure imaged by Ps and Sp receiver functions. J. Geophys. Res. 115, B09301 (2010).

34. B. Knapmeyer-Endrun, F. Krüger, the PASSEQ Working Group, Moho depth across the TransEuropean Suture Zone from P- and S-receiver functions. Geophys. J. Int. 197, 1048-1075 (2014).

35. J. F. Lawrence, P. M. Shearer, A global study of transition zone thickness using receiver functions. J. Geophys. Res., 111, B0630 (2006).

36. L. Vinnik, H. Chenet, J. Gagnepain-Beyneix, P. Lognonné, First seismic receiver functions on the Moon. Geophys. Res. Lett. 28, 3031-3034 (2001).

37. P. Lognonné, J. Gagnepain-Beyneix, H. Chenet. A new seismic model of the Moon: implication in terms of structure, formation and evolution. Earth Planet. Sci. Lett. 112, 27-44 (2003).

38. J.-R. Scholz et al., Detection, analysis and removal of glitches from InSight's seismic data from Mars. Earth and Space Science 7, e2020EA001317-T, doi:10.1029/2020EA001317 (2020).

39. J. M. Kolb, V. Lekic, Receiver function deconvolution using transdimensional hierarchical Bayesian inference. Geophys. J. Int. 193, 1791-1735 (2014).

40. B. L. N. Kennett, The removal of free surface interactions from three-component seismograms. Geophys. J. Int., 104, 153-163 (1991).

41. R. W. Clayton, R. A. Wiggins, Source shape estimation and deconvolution of teleseismic bodywaves, Geophys. J. Int. 47, 151-177, doi:10.1111/j.1365-246X.1976.tb01267.x (1976).

42. J. P. Ligorria, C. J. Ammon, Iterative deconvolution and receiver-function estimation. Bull. Seism. Soc. Am. 89, 1395-1400 (1999).

43. R. Kind, G. L. Kosarev, N. V. Petersen, Receiver functions at the stations of the German Regional Seismic Network (GRSN). Geophys. J. Int 121, 191-202 (1995).

44. K. Hannemann, F. Krüger, T. Dahm, D. Lange, Structure of the oceanic lithosphere and upper mantle north of the Gloria Fault in the eastern mid-Atlantic by receiver function analysis. $J$. Geophys. Res. 122, 7927-7950 (2017).

45. G. Helffrich, Extended-time multitaper frequency domain cross-correlation receiver function estimation. Bull. Seism. Soc. Am. 96, 344-347 (2006).

46. T. Shibutani, T. Ueno, K. Hirahara, Improvement in the extended-time multitaper receiver function estimation technique. Bull. Seis. Soc. Am. 98, 812-816 (2008).

47. Eagar, K.C., M.J. Fouch, FuncLab: A MATLAB interactive toolbox for handling receiver function datasets, Seis. Res. Lett. 83, doi:10.1785/gssrl.83.3.596 (2012).

48. G. D. Bensen et al., Processing seismic ambient noise data to obtain reliable broad-band surface wave dispersion measurements. Geophys. J. Int. 169, 1239-1260 (2007). 
49. R. S. M. De Plaen, T. Lecocq, C. Caudron, V. Ferrazzini, O. Francis, Single-station monitoring of volcanoes using seismic ambient noise. Geophys. Res. Lett. 43, 8511-8518 (2016).

50. Y. Ito, K. Shiomi, Seismic scatterers within subducting slab revealed from ambient noise autocorrelation. Geophys. Res. Lett. 39, L19303 (2012).

51. F. J. Sánchez-Sesma, M. Campillo, Retrieval of the Green's function from cross correlation: the canonical elastic problem. Bull. Seism. Soc. Am. 96, 1182-1191 (2006).

52. R. Snieder, Extracting the Green's function from the correlation of coda waves: A derivation based on stationary phase. Phys. Rev. E 69, 046610 (2004).

53. W. Sun, B. L. N. Kennett, Receiver structure from teleseisms: Autocorrelation and cross correlation. Geophys. Res. Lett. 43, 6234-6242 (2016).

54. InSight Marsquake Service, Mars Seismic Catalogue, InSight Mission; V1 2/1/2020. ETHZ, IPGP, JPL, ICL, ISAE-Supaero, MPS, Univ. Bristol. doi:10.12686/a6 (2020).

55. D. Clarke, L. Zaccarelli, N. M. Shapiro, F. Brenguier. Assessment of resolution and accuracy of the Moving Window Cross Spectral technique for monitoring crustal temporal variations using ambient seismic noise. Geophys. J. Int. 186, 867-882 (2011).

56. M. Schimmel et al., Seismic Noise Autocorrelations on Mars. Earth and Space Science Open Archive, doi:10.1002/essoar.10506669.1 (2021).

57. S. Ceylan et al., Companion guide to the marsquake catalog from InSight, Sols 0-478: Data content and non-seismic events. Physics Earth Planet. Int. 310, 106597, doi:10.1016/j.pepi.2020.106597 (2021).

58. M. Schimmel, Phase cross-correlations: design, comparisons and applications. Bull. Seismol. Soc. Am. 89, 1366-1378 (1999).

59. G. Taylor, S. Rost, G. Houseman, Crustal imaging across the North Anatolian Fault Zone from the autocorrelation of ambient seismic noise. Geophys. Res. Lett. 43, 2502-2509, doi:10.1002/2016GL067715 (2016).

60. P. Romero, M. Schimmel, Mapping the basement of the Ebro Basin in Spain with seismic ambient noise autocorrelations. J. Geophys. Res. 123, 5052-5067, doi:10.1029/2018JB015498 (2018).

61. M. Schimmel, E. Stutzmann, S. Ventosa, Low-frequency ambient noise autocorrelations: Waveforms and normal modes. Seism. Res. Lett. 89 (4), 1488-1496, doi:10.1785/0220180027 (2018).

62. C. Buffoni, M. Schimmel, N.C. Sabbione, M.L. Rosa, G. Connon, Crustal structure beneath Tierra del Fuego, Argentina, inferred from seismic P-wave receiver functions and ambient noise autocorrelations. Tectonophysics 751, 41-53, doi:10.1016/j.tecto.2018.12.013 (2019).

63. S. Ventosa, M. Schimmel, E. Stutzmann, Towards the processing of large data volumes with phase cross-correlation. Seism. Res. Lett. 90(4), 1663-1669, doi:10.1785/0220190022 (2019).

64. M. Schimmel, J. Gallart, Frequency-dependent phase coherence for noise suppression in seismic array data. J. Geophys. Res. 112, B04303, doi:10.1029/2006JB004680 (2007).

65. M. Schimmel, E. Stutzmann, J. Gallart, Using instantaneous phase coherence for signal extraction from ambient noise data at a local to a global scale. Geophys. J. Int. 184, 494-506, doi:10.1111/j.1365-246X.2010.04861.x (2011).

66. T. S. Pham, H. Tkalčić, On the feasibility and use of teleseismic P wave coda autocorrelation for mapping shallow seismic discontinuities. J. Geophys. Res. 122, 3776-3791 (2017).

67. J. C. VanDecar, R. S. Crosson, Determination of teleseismic relative phase arrival times using multi-channel cross-correlation and least squares. Bull. Seism. Soc. Am. 80, 150-169 (1990).

68. F. Bissig et al., Multifrequency Inversion of Ps and Sp Receiver Functions: Methodology and Application to USArray Data. J. Geophys. Res. 126, e2020JB020350, doi: 10.1029/2020JB020350 (2021).

69. A. Khan et al., A geophysical perspective on the bulk composition of Mars. J. Geophys. Res. 123, 1-37, doi: 10.1002/2017JE005371 (2018). 
70. K. Fuchs, G. Müller, Computation of synthetic seismograms with the reflectivity method and comparison with observations. Geophys. J. Int. 23, 417-433, doi:10.1111/j.1365246X.1971.tb01834.x (1971).

71. H. P. Crotwell, T. J. Owens, J. Ritsema, The TauP Toolkit: Flexible seismic travel-time and ray-path utilities. Seismol. Res. Lett. 70, 154-160, doi:10.1785/gssrl.70.2.154 (1999).

72. K. Mosegaard, A. Tarantola, Monte Carlo sampling of solutions to inverse problems. $J$. Geophys. Res. 100, 12431-12447, doi:10.1029/94JB03097 (1995).

73. A. Tarantola, Inverse problem theory and methods for model parameter estimation. Society of Industrial and Applied Mathematics (2005).

74. K. Mosegaard, A. Tarantola, Probabilistic Approach to Inverse Problems. In: International Handbook of Earthquake and Engineering Seismology, 237-265. Academic Press (2002).

75. M. Wathelet, An improved neighborhood algorithm: Parameter conditions and dynamic scaling. Geophys. Res.Lett. 35, L09301 (2008).

76. M. Sambridge, Geophysical inversion with a neighbourhood algorithm-I. Searching a parameter space. Geophys. J. Int. 138, 479-494 (1999).

77. R. Joshi, B. Knapmeyer-Endrun, K. Mosegaard, H. Igel, U. Christensen, Joint inversion of receiver functions and apparent incidence angles for sparse seismic data. Earth and Space Science Open Archive, doi:10.1002/essoar.10506471.1 (2021).

78. T. Shibutani, M. Sambridge, B. Kennett, Genetic algorithm in-version for receiver functions with application to crust and uppermost mantle structure beneath eastern Australia. Geophys. Res. Lett. 23, 1829-1832 (1996).

79. T. Nissen-Meyer et al., AxiSEM: Broadband 3-D seismic wavefields in axisymmetric media. Solid Earth 5, 425-445 (2014).

80. B. Knapmeyer-Endrun, S. Ceylan, S., M. van Driel, Crustal S-wave velocity from apparent incidence angles: a case study in preparation for InSight. Space Sci. Rev. 214, 83 (2018).

81. F. Birch, The velocities of compressional waves in rocks to 10 kilobars, Part 2. J. Geophys. Res. 66, 2199-2224 (1961).

82. N. Brinkman et al., First focal mechanisms of marsquakes. J. Geophys. Res. 126, e2020JE006546 (2021).

83. M. A. Wieczoreket al., The crust of the Moon as seen by GRAIL. Science 339, 671-675 (2013).

84. T. Yoshizaki, W. F. McDonough, The composition of Mars. Geochim. Cosmochim. Acta 273, 137-162 (2020).

85. M. A. Wieczorek and R. J. Phillips, Potential anomalies on a sphere: Applications to the thickness of the lunar crust, J. Geophys. Res. 103(E1), 1715-1724 (1998).

86. A. Broquet et al., Flexure of the lithosphere beneath the North Polar Cap of Mars: Implications for ice composition and heat flow. Geophys. Res. Lett. 47, e2019GL086746 (2020).

87. M. A. Wieczorek, Gravity and Topography of the Terrestrial Planets. Treatise on Geophysics, 2nd edition, Oxford, 153-193 (2015).

88. A. Genova et al., Seasonal and static gravity field of Mars from MGS, Mars Odyssey and MRO radio science, Icarus 272, 228-245 (2016).

89. T. Ruedas, D. Breuer, On the relative importance of thermal and chemical buoyancy in regular and impact-induced melting in a Mars-like planet, J. Geophys. Res. Planets 122, 1554-1579 (2017).

90. E. Takahashi, Speculations on the Archean mantle: missing link between komatiite and depleted garnet peridotite, J. Geophys. Res. 95, 15941-15954 (1990).

91. M. Duncan, N. Schmerr, C. M. Bertka, Y. Fei, Extending the solidus for a model iron-rich Martian mantle composition to 25 GPa. Geophys. Res. Lett. 45, 10,211- 10,220, doi:10.1029/2018GL078182 (2018).

92. A. C. Plesa, N. Tosi, M. Grott, D. Breuer, Thermal evolution and Urey ratio of Mars. $J$. Geophys. Res. Planets 120, 995-1010 (2015). 
93. N. Tosi, M. Grott, A.C. Plesa, D. Breuer, Thermochemical evolution of Mercury's interior. $J$. Geophys. Res. E Planets 118, 2474-2487 (2013).

94. A. Plesa et al., How large are present-day heat flux variations across the surface of Mars? $J$. Geophys. Res. 121, 2386-2403 (2016).

95. W. K. Hartmann, Evidence for recent volcanism on Mars from crater counts. Nature 397, 586589 (1999).

96. G. Neukum, Recent and episodic volcanic and glacial activity on Mars revealed by the High Resolution Stereo Camera, Nature 432, 971-979 (2004).

97. M. Thiriet, D. Breuer, C. Michaut, A.-C. Plesa, Scaling laws of convection for cooling planets in a stagnant lid regime. Phys. Earth Planet. Inter. 286, 138-153 (2019).

98. W. V. Boynton et al., Concentration of $\mathrm{H}, \mathrm{Si}, \mathrm{Cl}, \mathrm{K}, \mathrm{Fe}$, and $\mathrm{Th}$ in the low- and mid-latitude regions of Mars. J. Geophys. Res. 112, E12S99, doi:10.1029/2007JE002887 (2007).

99. H. E. Newsom et al., Geochemistry of Martian soil and bedrock in mantled and less mantled terrains with gamma ray data from Mars Odyssey. J. Geophys. Res. 112, E03S12, doi:10.1029/2006JE002680 (2007).

100.H. Y. McSween Jr, S. M. McLennan, Mars. In: H. D. Holland and K. Turekian, eds., Treatise on Geochemistry, 2nd Ed.; Vol. 2, A. M. Davis, ed., Planets, Asteroids, Comets and The Solar System (Elsevier, Amsterdam) pp. 251-300 (2014).

101.C. B. Agee et al. Unique meteorite from early Amazonian Mars: Water-rich basaltic breccia Northwest Africa 7034. Science 339, 780-785, doi:10.1126/science.1228858 (2013).

102.B. C.Hahn, B. C. et al., Mars Odyssey gamma-ray spectrometer elemental abundances and apparent relative surface age: Implications for martian crustal evolution. J. Geophys. Res. 112, E03S11, doi:10.1029/2006JE002821 (2007).

103.S. Karunatillake et al., Chemically striking regions on Mars and Stealth revisited. J. Geophys. Res. 114, E12001, doi:10.1029/2008JE03303 (2009).

104.G. J. Taylor et al., Mapping Mars geochemically. Geology 38, 183-186, doi:10.1130/G30470 (2010).

105.P. L. King, S. M. McLennan, Sulfur on Mars. Elements 6, 107-112 (2010).

106.C. L. Johnson et al., Crustal and time-varying magnetic fields at the InSight landing site on Mars. Nature Geoscience 13, 199-204 (2020).

107.B. Langlais et al. A new model of the crustal magnetic field of Mars using MGS and MAVEN. J. Geophy. Res. 124, 1542-1569 (2019).

108.A. Mittelholz, C. L. Johnson, A. Morschhauser. A new magnetic field activity proxy for Mars from MAVEN data. Geophys. Res. Lett. 45, 5899-5907 (2018).

109.R. L. Parker, Ideal bodies for Mars magnetics. J. Geophys. Res. 108, 5006 (2003).

110.A. Mittelholz, C. L. Johnson, J. M. Feinberg, B. Langlais, R. J. Phillips, Timing of the martian dynamo: New constraints for a core field 4.5 and $3.7 \mathrm{Ga}$ ago. Science Advances 6 (2020).

111.A. S. Konopliv et al. Detection of the Chandler wobble of Mars from orbiting spacecraft. Geophys. Res. Lett. 47, e2020GL090568, doi:10.1029/2020GL090568 (2020).

112.D. Kahan et al., Mars precession rate determined from radiometric tracking of the InSight lander. Planet. Space Sci. 199, 105208, doi:10.1016/j.pss.2021.105208 (2021).

113.M. P. Panning et al., Planned products of the Mars structure service for the InSight mission to Mars. Space Sci. Rev. 211, 611-650 (2017).

114.A. Rivoldini, T. Van Hoolst, O. Verhoeven, A. Mocquet, V. Dehant, Geodesy constraints on the interior structure and composition of Mars. Icarus 213, 451-472, doi:10.1016/j.icarus.2011.03.024 (2011).

115.J. A. D. Connolly, Computation of phase equilibria by linear programming: A tool for geodynamic modeling and its application to subduction zone decarbonation. Earth Planet. Sci. Lett. 236, 524-541, doi:10.1016/j.epsl.2005.04.033 (2005).

116.L. Stixrude, C. Lithgow-Bertelloni, Thermodynamics of mantle minerals - II. Phase equilibria. Geophys. J. Int. 184, 1180-1213, doi:10.1111/j.1365-246X.2010.04890.x (2011). 
117.G. J. Taylor et al., Variations in K/Th on Mars. J. Geophys. Res. 111, E03S06, doi:10.1029/2006JE002676 (2007).

Acknowledgments: This is Insight Contribution Number (ICN) 187. We acknowledge NASA, CNES, their partner agencies and institutions (UKSA, SSO, DLR, JPL, IPGP-CNRS, ETHZ, IC, MPS-MPG) and the flight operations team at JPL, SISMOC, MSDS, IRIS-DMC and PDS for providing SEED SEIS data. Funding: MPP, ST, EB, SES, and WBB were supported by the NASA InSight mission and funds from the Jet Propulsion Laboratory, California Institute of Technology, under a contract with the National Aeronautics and Space Administration. FB was supported by research grant ETH-05 17-1. AK, DG, MVD and SS acknowledge funding by the Swiss National Science Foundation, the Swiss State Secretariat for Education, Research and Innovation, and support from ETHZ through the ETH+ funding scheme (ETH+02 19-1). VL and DK acknowledge funding from Packard Foundation Fellowship to VL. BT is supported by the European Union's Horizon 2020 research and innovation program under the Marie Sklodowska-Curie grant agreement 793824. French co-authors acknowledge the support of CNES and ANR (MAGIS, ANR-19CE31-0008-08). NS was supported by NASA Grant 80NSSC18K1628. EB was funded through NASA Participating Scientist Program Grant 80NSSC18K1680. ACP gratefully acknowledges the financial support and endorsement from the DLR Management Board Young Research Group Leader Program and the Executive Board Member for Space Research and Technology. Geodynamical models used in this work were performed on the supercomputer ForHLR funded by the Ministry of Science, Research and the Arts Baden-Württemberg and by the Federal Ministry of Education and Research. SMM was funded through NASA InSight Participating Scientist Program Award No. 80NSSC18K1622. CM acknowledges the support of the Institut Universitaire de France (IUF). CLJ and AM acknowledge support from the InSight Mission, the Canadian Space Agency and ETH Zurich (ETH fellowship 19-2 FEL-34). NB is supported by research grant ETH-06 17-02. The work of AR was financially supported by the Belgian PRODEX program managed by the European Space Agency in collaboration with the Belgian Federal Science Policy Office. Author contributions: BKE, MPP, FB, RJ, AK, DK, VL, BT, ST, MP, NC, RFG, LM, MS, ES, NS, ACP, MW, DA, SMM, HS, CM, LP, SES, CLJ, PL, MK, DG and WBB contributed to the conceptualization of this study. The applied methodologies were developed by BKE, FB, RJ, AK, DK, VL, BT, ST, MP, NC, RFG, LM, MS, ES, ACP, MW, HS, CM, LP, PMD, PL, BP and JRS. BKE, FB, RJ, AK, DK, NC, MS, ES, ACP, MW, HS, CM, PMD, PL, BP and JRS developed, implemented and tested used software. BKE, MPP, NS, NB and MVD provided validation. Formal analyses were conducted by BKE, RB, RJ, AK, DK, VL, BT, ST, MP, NC, MS, ES, ACP, MW, AB, HS, CM, CLJ, NB, AM, AR, PMD, PL, BP, JRS and SS. BKE, FB, RJ, AK, DK, VL, ST, MP, NC, MS, ES, ACP, MW, SMM, HS, CM, CLJ, NB, AM, AR, PMD, PL, BP, JRS and SS provided investigations. Data curation activities were done by PL, SS, MVD and DG. BKE, MPP, FB, RJ, AK, DK, VL, BT, ST, NC, RFG, LM, MS, ES, ACP, MW, SMM, HS, $\mathrm{CM}, \mathrm{CLJ}, \mathrm{NB}, \mathrm{AM}, \mathrm{AR}$ and PMD contributed to the writing of the original draft. Review and editing were performed by BKE, MPP, NS, EB, AB, DA, SES, CLJ and MK. BKE, MPP, FB, RJ, AK, DK, VL, BT, NC, MS, ES, NS, ACP, MW, HS, CM, AM, AR and PMD worked on visualizing the results. BKE, MPP, AK, RFG, LM, NS, CLJ, PL and DG supervised junior scientists involved in the project. The project was administrated by SES, PL, DG and WBB, who also acquired funding. Competing interests: Authors declare no competing interests. Data and materials availability: All InSight SEIS data (32) used in this paper are available from the IPGP Data Center, IRIS-DMC and NASA PDS.

\section{Supplementary Materials:}

Materials and Methods

Figures S1-S29

Tables S1-S6

References (33-117) 

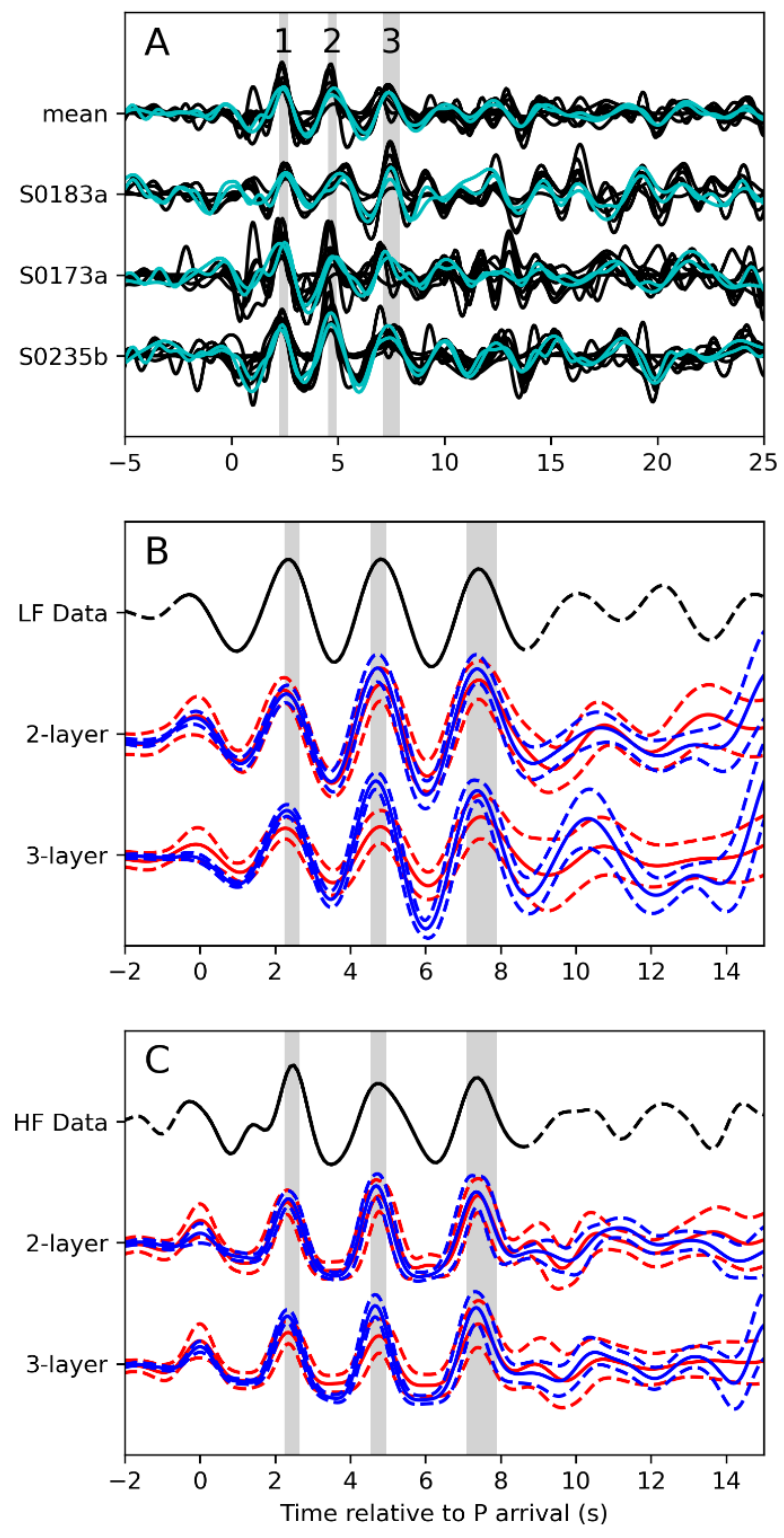

Fig. 1. Measured and modeled converted phases that constrain the crustal structure at the InSight landing site. (A) P-to-S receiver functions for the three events considered, and the summed trace. Different traces for each event correspond to different processing methods as described in the Supplementary Materials. Gray shading highlights the three clear positive phases within the first $8 \mathrm{~s}$. Numbered labels correspond to predicted ray paths shown in Fig. 2B,D. The two datasets used for model inversions shown in Fig. 2 are highlighted in cyan. (B) Comparison between the low-frequency representative receiver function sum trace and synthetic summed P-to-S receiver functions for the 2- and 3-layer models. Data is shown in black on top, with the time window used in the inversion drawn solid. Solid and dashed red lines show the synthetics computed by the range of models produced by inversion method A (16), while solid and dashed blue lines show the mean receiver functions with standard deviations based on the 5000 best fitting receiver functions derived from inversion method B (16). Gray shaded regions are the same as in (A). (C) Same as panel (B), but for the high-frequency receiver functions. 

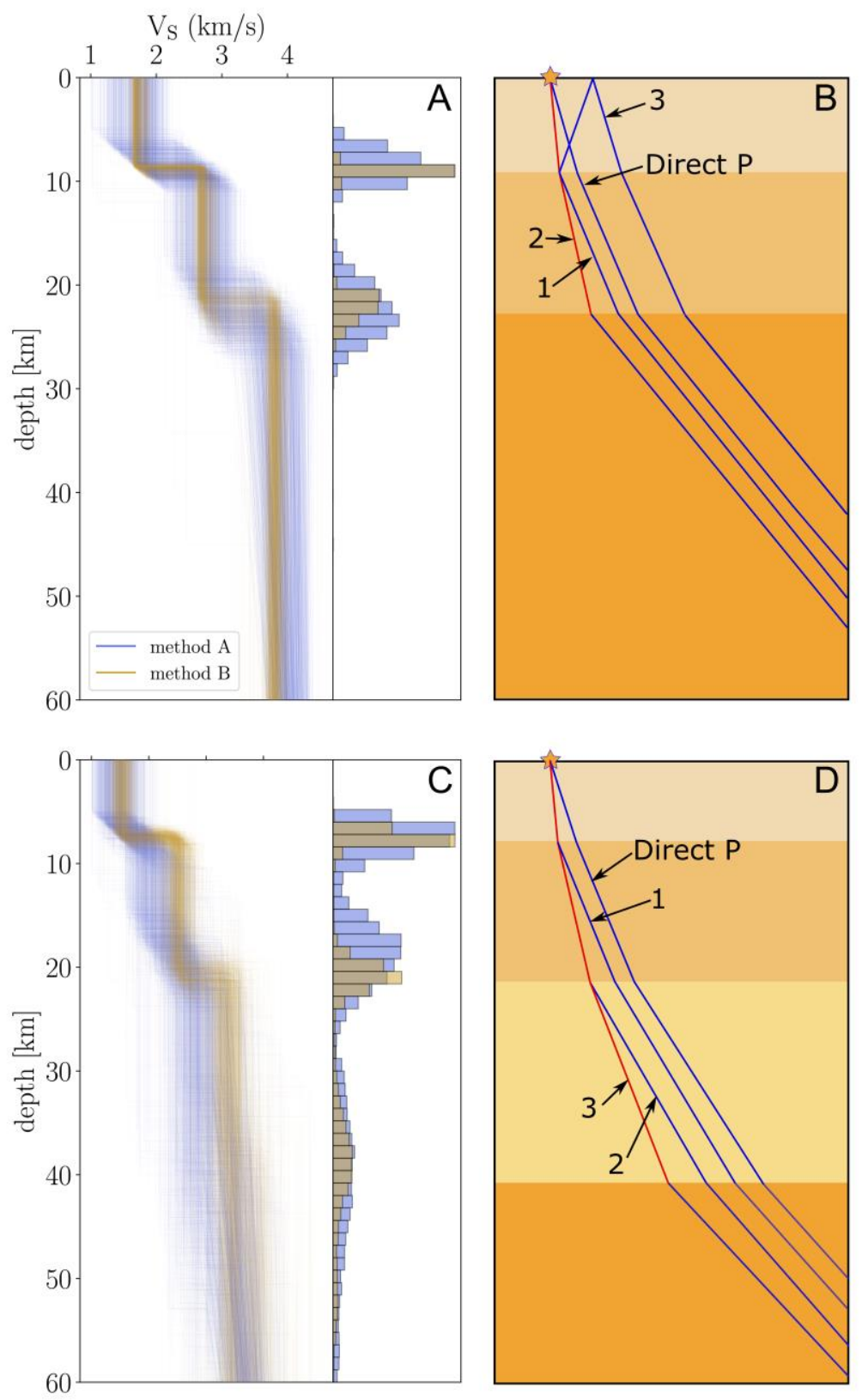

Fig. 2. Synopsis of the crustal structure of Mars at the InSight landing site from receiver function analyses. (A) Inversion results for all three events using inversion method A (in blue lines) and method B (in brown) using a two-layer parameterization. (B) Cartoon showing the ray paths of the main direct and converted phases present in the data. Blue lines show $\mathrm{P}$ phase paths, while the red lines show conversions to $\mathrm{S}$ phases at the interfaces below the lander. Direct conversions and one $\mathrm{P}$ multiple are shown and numbered labels correspond to arrivals identified in Fig. 1A. (C-D) Same as (A-B), except for assuming a three-layer model and excluding the multiple arrival. 


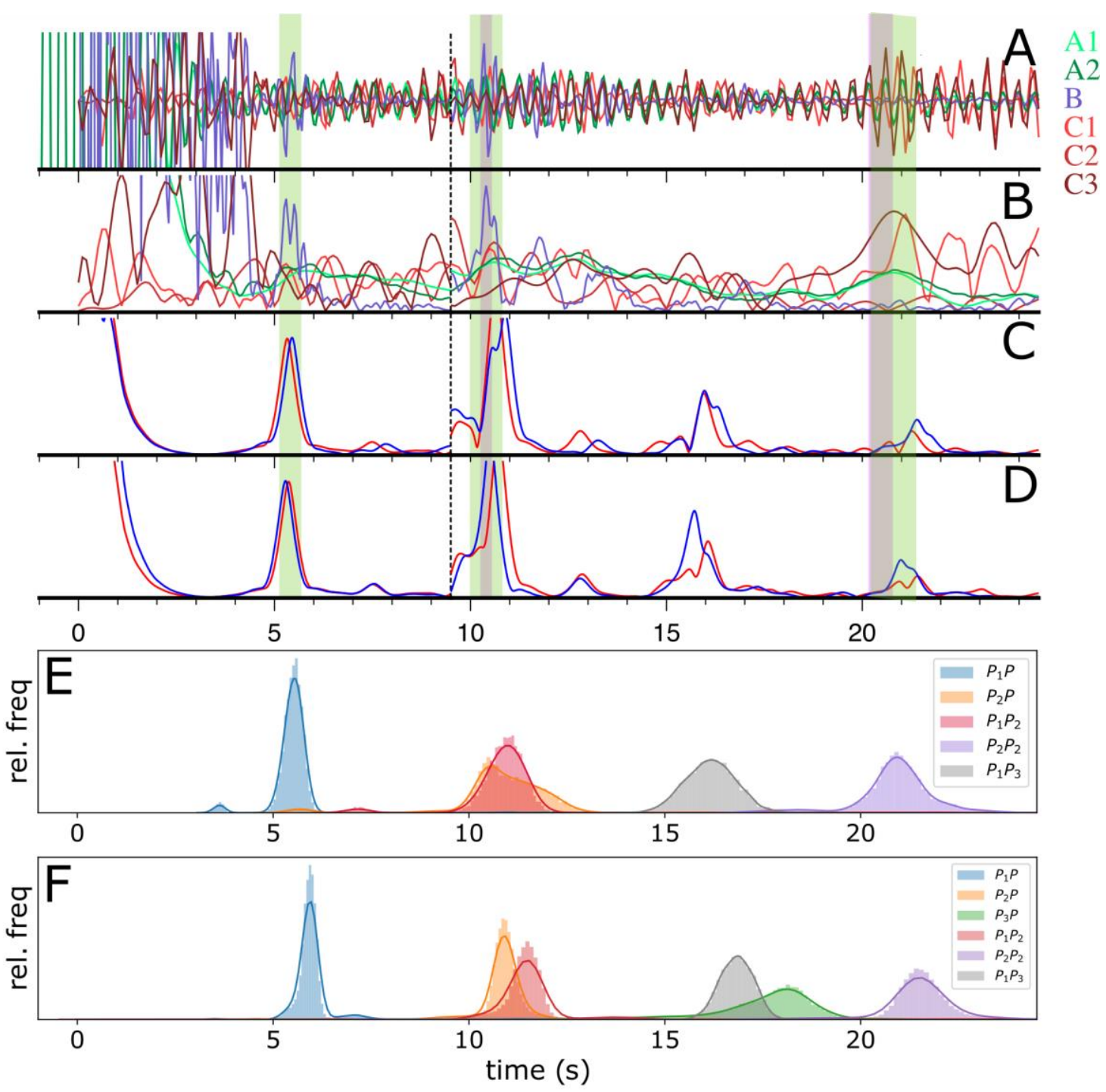

Fig. 3. Autocorrelation functions for different data sets, components, and processing methods. (A) Overlaid traces are from the three analysis methods discussed in the supplementary material. The dashed bar at $9.5 \mathrm{~s}$ corresponds to a change in normalization in order to see smaller amplitude arrivals later in the trace. Green bars highlight areas where all methods are nearly in-phase and show potential arrivals, whereas purple bars highlight arrivals indicated from an independent study (24). (B) Envelopes of the ACFs displayed in (A). (C) Envelopes of synthetic zero-offset Green's functions for a representative model from the family of two-layer models in Fig. 2A for method A in blue and method B in red. (D) Same as (C), but for the three-layer models from Fig. 2C. (E) Histograms of predicted arrivals from the family of two-layer models as shown in Fig. 2A. The first subscript of the arrival in the legend refers to the interface of reflection, and the second subscript (if present) represents a second or third bounce between the free surface and that interface. (F) Same as (E), but for the three-layer models in Fig. 2C. 


\section{A) Thin Crust}

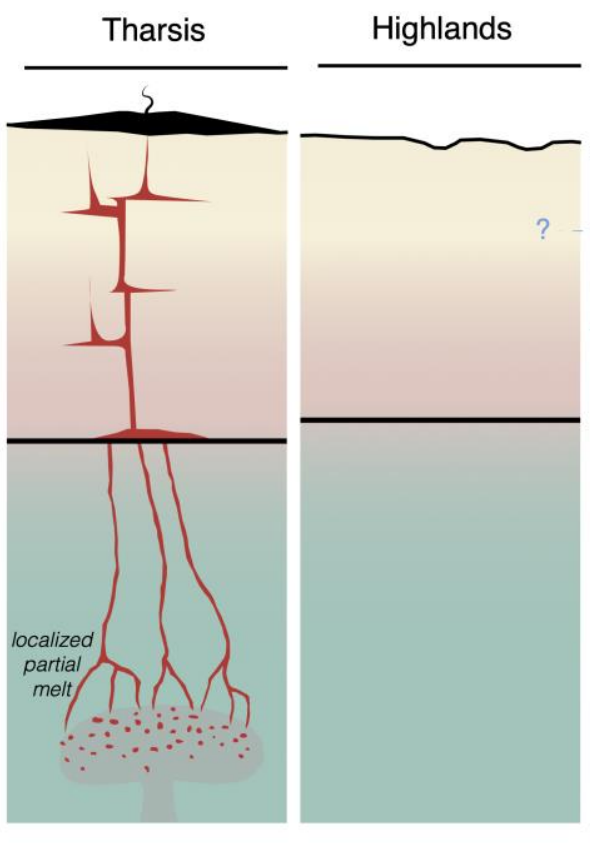
InSight \& Lowlands

Global Average

B) Thick Crust
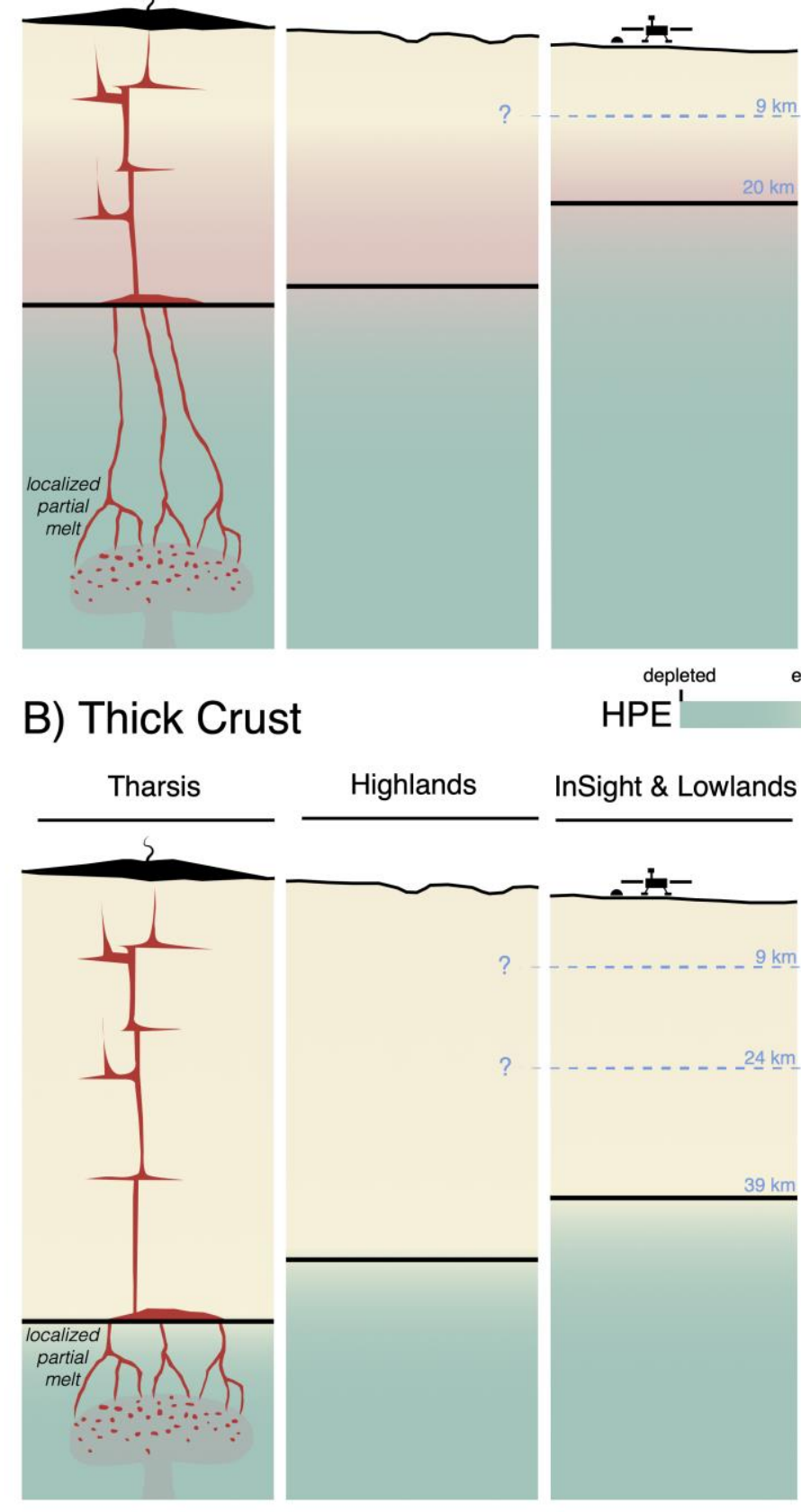
$\frac{\text { sडs 20-25 mWm-2 }}{\text { Crust }}$

$\rho_{\text {crust }}<2900 \mathrm{~kg} \mathrm{~m}^{-3}$

more felsic than surface

Moho

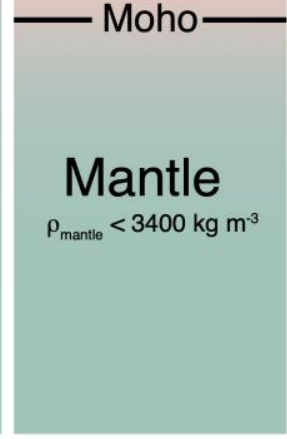

depleted
HPE $^{\prime}$

enriched

highly enriched InSight \& Lowlands Global Average
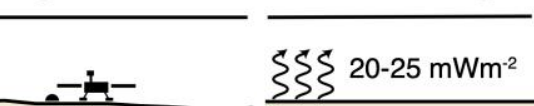

Fig. 4. Schematic interpretations of the geochemical and geodynamical implications for the thin and thick crust models (A and $\mathbf{B}$, respectively). In order to match geodynamic constraints, an enrichment of heat producing elements, shown in color, and lower density than observed from the surface are required in the thin crust model, whereas the thick crust model is consistent with surface observations. 